\title{
JOURNALISTS' ATTITUDE TOWARDS MATERNAL HEALTH EDUCATION BROADCAST ON RADIO IN OYO STATE, NIGERIA
}

\author{
Thomas KA*, Tijani SA and Seidu AA \\ Department of Agricultural Extension and Rural Development, University of Ibadan, Nigeria
}

Accepted: 17 April 2011

\begin{abstract}
The study investigated journalists' attitude towards maternal health education (MHE) broadcast on radio in Oyo State, Nigeria. One hundred journalists were surveyed randomly from the federal, state and privately owned radio stations in Oyo state. Data were collected using structured questionnaires and analysed using frequency distribution, percentage, chi-square and t-test. Results showed that majority $(54 \%)$ were males and within the age of 29- 30 years. They all have formal education with majority $(72 \%)$ having work experience more than 5 years. Knowledge of maternal health was high (65\%) and $(52 \%)$ had favourable disposition to MHE. Constraints faced by journalist were lack of sponsors and lack of funds. Inferential statistics revealed that education $\left(\chi^{2}=9.55, p<0.005\right)$, radio stations ownership $\left(\chi^{2}=16.45, P<0.005\right)$ and programmes aired $\left(\chi^{2}=0.20, p<0.005\right)$ were significantly related to journalists' attitude to MHE broadcast on radio. Similarly, significant difference $(t=29.15, p<0.005)$ exist between male and female journalists' attitude to MHE broadcast on radio. Proper education, gender main streaming and adequate funding are panacea to MHE broadcast on radio.
\end{abstract}

Key words: Journalist, Attitude, Maternal Health, Broadcast, Radio

\section{INTRODUCTION}

Nigeria has population of 140 million people with about 31 million women of child bearing age. (National Population Commission (NPC) 2006). Nigeria constitutes $1 \%$ of the world population and $10 \%$ of the world's Maternal and under-5 Mortality rates. Annually, 52,900 Nigerian women die from pregnancy related complications out of total 529,000 global maternal deaths. One out of every 13 women die from pregnancy and childbirth in Nigeria (compared with 1:5000 in developed nations); where about $40 \%$ of deliveries are being attended to by skilled attendants. The best estimates (due to high variation and controversy) suggest that about 54,000 Nigerian women and girls die each year due to pregnancy related issues, while $1,080,000$ to $1,620,000$ Nigerian women and girls suffer from disabilities caused by complications during pregnancy and childbirth each year (WHO/UNICEF/UNFPA 1995)

At a WHO conference in 2005 , it was agreed that Nigeria should explore opportunities for

\footnotetext{
*Corresponding author: kehindeadesina@yahoo.com
}

adopting the 5 identified quick wins for Maternal Mortality Ratio reduction; Establishment of Ministerial forum on Maternal, New-born and Child Health (MNCH): Deployment of two youth corps doctors and at least five midwives [newly qualified basic and post basic midwives] to each of the 774 LGAs in the country: Accelerate promotion of key family practices to create demand and develop advocacy messages towards improving $\mathrm{MNCH}$ : Institutionalize outreach services to address $\mathrm{MNCH}$ : Ensure universal access to effective family planning information and services to all Nigerians (WHO 2005)

Some factors responsible for the insignificant progress made in reducing this mortality rate include disparity between accesses, care received, service capacity, policy supporting safe motherhood in rural areas and urban centre. [Mid Point Assessment Overview, MDGs Nigeria Sept 2008]. This gap can be bridged by the use of media which is an efficient and less expensive method of informing and influencing people. There is, however, a shortage of media 
specialists in developing countries; especially those associated with MHE related programmes (Stuart 1993a). The incorporation of these specialists will lead to women rejecting traditional health practices for professional antenatal care. Popular entertainment such as dance, drama and music on radio can also be used creatively. The media can also set the paceof public discussion and influence public policy on maternal health education.

Reaching the unreached through this mass media can be guaranteed because most homes have access to at least one medium of information (especially radio). For example, it was discovered that $62 \%$ of rural and $85 \%$ of urban households have radio receivers while majority of the people in rural areas are medically underserved and thus depend on the radio as their main source of health information (Women's Health and Action Research Centre, 2004).

\section{METHODOLOGY}

Area of study: The area of study was Oyo state, Nigeria. Its capital is Ibadan and has 33 local government areas. It is located in the South-Western part of Nigeria. Oyo State was created out of the former Western State by Federal Military Government on the $3^{\text {rd }}$ of February, 1976. It lies between latitude $7^{0}$ and $9^{0} 3$ of the equator and between longitude $2.5^{\circ}$ and $5^{\circ} \mathrm{E}$ of the prime meridian. It covers a total area of about $27,249 \mathrm{~km}^{2}$; it is bounded in the north, south, east and west by kwara State, Osun State, Ogun State and partly by the Republic of Benin respectively. Oyo state has a population of 5,591,589 people (NPC 2006).

Multistage random sampling technique was used. The radio stations in the state which include; Splash FM, Diamond FM, Premier FM, Amuludun FM, Ajilete FM, OkeOgun FM, Oluyole FM, FRCN Ibadan (RN1) AM, BCOS Radiol(Saki), BCOS Radiol and (Ogbomosho) FM. were stratified according to their ownership - Federal, state and privately owned. Random sampling technique was use to select one radio station each from federal, state and privately owned while a list of journalists was compiled from the selected radio stations and probability proportional sample to size method was used to select the journalists for the study. This includes 46 journalists from Premier FM, 8 from Splash FM and 46 from BCOS radio to give one hundred journalists used for the survey.

Primary data were obtained through the use of structured questionnaire which contain open and closed ended questions. Descriptive and inferential statistics were used to analyse the data.

\section{RESULTS AND DISCUSSION}

Personal Characteristics of Respondents: Majority of the respondents are still in active age group with $27 \%$ being between $15-25 ; 44 \%$ being between $26-35 ; 23 \%$ between $36-45$ and $6 \%$ between 46-55.This implies that they will be able to carry out their work effectively and thus improve their efficiency. Skirrbekk (2003) cites some studies which show that the differences between age groups are larger in crosssection studies than in longitudinal studies. It implies that young journalists will likely campaign more for an improved maternal health education through radio.

There were more male journalists $(54 \%)$ than female journalists $(46 \%)$ in the study area. This implies that male attitudes towards maternal health education broadcast may be affected because of the natural instinct associated with maternal health wherein the subject is consented to motherhood affair. Lack of male involvement in HIV programmes is a major bottleneck to effective programme implementation (Horizons Programme Report 2002).

Religion has variable pattern of association with service utilization, with significant association in some settings but not in some others. Note that roles differ across geographic and social setting and the determinants of maternal 
health care service utilization vary across and within cultures (Gyimah et al 2006). Hence, $98 \%$ of the respondents were either Christians or Muslims. Majority (41\%) of the respondents were married. This will enhance greater interest and anticipation in MHE broadcast as well as improving their participation and effectiveness in broadcast. Hence, there is prospect for MHE broadcast to thrive in an environment where we have more married journalists.

Also, all of the respondents have one form of education or the other, where $14 \%$ had OND, $26 \%$ had HND, 37\% had BSc and 22\% had M.Sc. This implies that majority of the respondents can comfortably harness information on maternal health education. Ensor and Cooper, (2004) also said that better education can lead to general improvement of literacy and health knowledge, increased desire for, and use of health services. Kessler (1991) finds that family size is both a statistical and economical determinant of women's employment status. Angrist and Evans (1998) estimated the impact of childbearing on women's labour supply; more children would lead to a reduction in mother's labour supply and this reduction is more likely to be severe for poor and less educated women. It implies that respondents with more children $(60 \%)$ have more roles to play to ensure better service delivery in media house, even when they have passion for maternal health broadcast because of experience of parenthood, there social roles at the home might be an hindrance to perform well.

Result reveals that majority of the respondents were into news and current affairs (45\%). Unemployment rate in Nigeria is still very high making the people who build career around area of specialization in schools very small. Hence, they stick to any job they find. Likewise, most of the people working in the media house surveyed were not professional journalist but rather gain their expertise on the job. It implies that, efficiency and professionalism may likely drop because more often than not lack of employment is what drove many into journal- ism. More than half of the respondents had 1-5 years working experience. This gives an indication that their experience on the job may likely boost interest in the subject matter.

Distribution of Health Related Broadcast on Radio: The distribution of health broadcast on a daily, weekly and monthly bases are $26 \%$, $67 \%$ and $7 \%$ respectively. Recently in Nepal, a study was done and was designed to include distance education for Female Community Health Volunteers (FCHVs) and drama serials for the general public in collaboration with the National Health Education, Information and Communication Centre. Based on annual FCHV surveys, the proportion of FCHVs that listened to the distance education radio program at least once in the six weeks prior to the survey increased from $57 \%$ in 2004 to $83 \%$ in 2005 to $87 \%$ in 2006 . While $26 \%$ and $20 \%$ of men and women respectively between the ages of 15-59 were exposed to the drama serial 'GyanNai Shakti Ho'. Hence the proportion of exposure was higher in areas where radios had been distributed, as this increase in exposure appears to correlate with the timing of radio distributions to FCHVs. Therefore, the frequency of programme broadcast can influence listenership and then a change in desire health outcome.

\section{Respondents' knowledge of maternal health education}

Knowledge Scores: Mean knowledge score as shown in table 3 for the 13 questions on knowledge of maternal health. The mean score was 14.21 (+-2.1). Mean and above is considered to be high knowledge, while below mean is low knowledge. Majority of the journalists surveyed had never received any formal training on maternal health. Some of the respondents knew the necessities of seeking antenatal care but majority didn't know first care-seeking that should be done within the first trimester of pregnancy as well as handling possible urgent problems at home.

Almost $24 \%$ of them didn't know correct actions after amniotic fluid breaks. 
Table 1: Distribution of Respondents According to Their Personal Characteristics

\begin{tabular}{|c|c|c|c|}
\hline Variables & $\begin{array}{l}\text { Fre- } \\
\text { quency } \\
(\mathrm{N}=\mathbf{1 0 0}) \\
\end{array}$ & Variables & $\begin{array}{l}\text { Fre- } \\
\text { quency } \\
(\mathrm{N}=\mathbf{1 0 0}) \\
\end{array}$ \\
\hline$\overline{\text { Age }}$ & & Family size & \\
\hline $15-25$ & 27 & $1-3$ & 34 \\
\hline $26-35$ & 44 & $4-6$ & 60 \\
\hline $36-45$ & 23 & $7-9$ & 6 \\
\hline $46-55$ & 6 & Year of Experience & \\
\hline Sex & & $1-5$ & 72 \\
\hline Male & 54 & $6-10$ & 15 \\
\hline Female & 46 & $11-15$ & 5 \\
\hline Religion & & $16-20$ & 7 \\
\hline Christianity & 73 & $21-25$ & 1 \\
\hline Islam & 25 & Area Of Specialization & \\
\hline Traditional & 2 & News and current affairs & 45 \\
\hline Marital status & & Sports & 7 \\
\hline Single & 54 & News editors & 16 \\
\hline Married & 41 & Programmer/Computer an & \\
\hline Divorced & 5 & Presenter/ producer & 10 \\
\hline Educational level & & Marketing & 10 \\
\hline Secondary & 1 & Engineering & 6 \\
\hline OND & 14 & Family size & \\
\hline HND & 26 & $1-3$ & 34 \\
\hline B.Sc. & 37 & $4-6$ & 60 \\
\hline M.Sc. & 22 & $7-9$ & 6 \\
\hline Family size & & Year of Experience & \\
\hline $1-3$ & 34 & $1-5$ & 72 \\
\hline $4-6$ & 60 & $6-10$ & 15 \\
\hline $7-9$ & 6 & $11-15$ & 5 \\
\hline Year of Experience & & $16-20$ & 7 \\
\hline $1-5$ & 72 & $21-25$ & 1 \\
\hline $6-10$ & 15 & Area of Specialization & \\
\hline $11-15$ & 5 & News and current affairs & 45 \\
\hline $16-20$ & 7 & Sports & 7 \\
\hline \multirow[t]{5}{*}{$21-25$} & 1 & News editors & 16 \\
\hline & & \multicolumn{2}{|c|}{ Programmer/Computer analyst6 } \\
\hline & & Presenter/ producer & 10 \\
\hline & & Marketing & 10 \\
\hline & & Engineering & 6 \\
\hline
\end{tabular}

Table 2: Frequency Distribution of Health Related Broadcast on Radio

\begin{tabular}{lll}
\hline Frequency of broadcast & Frequency $(\mathrm{N}=100)$ & Percentage \\
\hline Daily & 26 & 26.0 \\
Weekly & 67 & 67.0 \\
Monthly & 7 & 7.0 \\
\hline
\end{tabular}

For the test of knowledge, more respondents had a low knowledge (60\%) while only $40 \%$ had high knowledge of MHE. Some selected personal characteristics were found to influence the knowledge of MHE. This includes years of experience and education. It is expected that educated women are more likely to be aware of their health status and seek health knowledge as well as a greater decision making power on health related matters. Ohnishi, Nakamura and Takano (2005), in a study conducted in Paraguay reported that MHE knowledge would be improved with wide application of community-based antenatal care programme to meet the needs of those who are functionally illiterate. It is obvious that women with least knowledge on maternal health would be the one who had least access to maternal care services.

\section{Respondents' attitude on maternal health}

Table 3: Distribution of respondents according to knowledge scores

\begin{tabular}{lll}
\hline Knowledge scores & Frequency $(\mathrm{n}=100)$ & Percentage \\
\hline $5-10$ & 3 & 3.0 \\
$11-15$ & 65 & 65.0 \\
$16-20$ & 32 & 32.0 \\
\hline
\end{tabular}

education (MHE): Table 4 reveals that virtually all agreed that journalist have an important role to play in reducing maternal mortality and thereby increasing the need for MHE. On the whole journalist had a mean score of $59.0(+-$ 2.1). Mean and above is considered to be high knowledge, while below mean is low knowledge. The positive attitude exhibited by the journalists is a pointer for opportunity to channel maternal education through radio and consequently improves the level of women educa- 
tion on maternal health. Education, the most critical determinant of woman health, means women benefit through increased knowledge to protect health and seek proper health care. This effect will transcend generations. In addition, education for women and girls results in better health, education and welfare outcomes for children and families. Female literacy rate is a strong predictor of maternal mortality rate (State of the world's children, 2004).

Constraint to maternal health education (MHE) broadcast on radio: The major con-

Table 4: Respondents' attitude to maternal health education

\begin{tabular}{lllc}
\hline Attitude & Frequency $(\mathrm{n}=100)$ & Percentage & mean score \\
\hline $38-49$ & 18 & 18.0 & 59.0 \\
$50-60$ & 37 & 37.0 & \\
$61-70$ & 35 & 35.0 & \\
$71-91$ & 10 & 10.0 & \\
\hline
\end{tabular}

straints being faced by respondents were lack of sponsors $(43 \%)$, lack of in-house experts on maternal health broadcast $(26 \%)$ and Cost of broadcasting health related issues (26\%). As a result of this, only programmes with sponsors are settled for by radio stations, hence, affecting journalists' attitude negatively on the long run. Generally, developing countries alike, there is little investment in ICTs (radio inclusive) for health making most media houses largely depend on sponsors for health related programmes. It is this view that WHO (2004) makes the point that technologies must be 'integrated into health services that meet basic needs' if they are to be considered to be essential investments.

There is a significant relationship between educational achievement of respondents and attitudes towards MHE broadcast on radio $\left(\chi^{2}=\right.$ $0.190, p<0.05)($ Table 5). Education is one of many indices of socioeconomic variable that has strong positive relationship between infant and child mortality. This is not limited to mother education alone but also applicable to maternal education training for journalist. All the respondents had one form of education or the other. This will enhance training in maternal health education for better utilization and delivery of maternal health messages on radio for women of child bearing age. Table 5 shows that there is a significant relationship between radio stations ownership and attitudes towards maternal health education broadcast on radio. $\left(\chi^{2}=16.453, p<0.05\right)$. There are a number of factors that can be associated with radio station ownership, this include funding, flexibility in radio programmes, career prospect, staff motivation and remuneration. Federal radio establishment in Nigeria are better remunerated than state and privately owned radio station. This in a way can affect attitude to delivery not only in maternal health but in other assigned duties.

Table 5: Chi Square Result on the Relationship between Educations, Radio Station, Ownership and

\begin{tabular}{lllll}
\hline Variable & $\chi^{2}$ value & Df & p value & Decision \\
\hline Education & 9.553 & 5 & 0.19 & $\mathrm{~S}$ \\
Radio station & 16.453 & 2 & 0.000 & $\mathrm{~S}$ \\
\hline
\end{tabular}

Difference between the attitudes of male and female journalist: There is significant difference between the attitudes of male and female journalist in the study area $(t=29.147, p=$ 0.000) (Table 6). Male-female differences in health vary in magnitude across different health conditions. Some health conditions are determined primarily by biological sex differences. Others are the result of how societies socialize women and men into gender roles supported by norms about masculinity and femininity, and power relations that accord privileges to men, but which adversely affect the health of both women and men. Where biological sex differences interact with social determinants to define different needs for women and men in health, policy efforts must address these different needs.

\section{CONCLUSIONS}

We conclude that radio station ownership is significantly related to journalists' attitudes to 
Table 6: Difference between the attitudes of male and female journalist in the study area

\begin{tabular}{lccll}
\hline Variables & Df & t- value & P - value & Decision \\
\hline Attitude & 99 & 29.147 & .000 & Significant \\
\hline
\end{tabular}

MHE broadcast on radio. Observed a positive relationship between education and journalists' attitudes to MHE education broadcast on radio. The major constraint to maternal health broadcast on radio is lack of sponsorship for MHE programs. Lastly, respondents had a favourably attitude to MHE. We recommend that workshop on gender main streaming should be organized for the journalist to promote image and attitude towards MHE broadcast on radio. There should be an adequate funding of MHE programmes by government and non- governmental agencies.

\section{REFERENCES}

Allison PD, Long JS 1990 Departmental effects on scientific productivity. Am. Sociol. Rev. 55(4) 469-478.

Angrist, Joshua and William Evans 1998 Children and Their Parents' Labor Supply: Evidence from Exogenous Variation in Family Size. American Economic Review. Vol. 88 No.3, June 1998.

Ann M Veneman 2007 Education Is Key To Reducing Child Mortality: The Link Between Maternal Health And Education UN Chronicle, Volume Xliv Number 4.

Gyimah SO, Takyi BK, Addai I 2006 Challenges to the reproductive-health needs of African women: on religion and maternal health utilization in Ghana. Social Science and Medicine 2006, 62:2930-2944.

Hill K, AbouZahr C and Wardlaw T 2001 "Estimates of Maternal Mortality for 1995." Bulletin of the World Health Organization 79 (3): 182193.

Horizons Programme Report (2002) 'Integrating HIV Prevention and Care into Maternal and Child Health Care Settings. Lessons Learned from Horizons studies', in Kenya Consultation report, Maasai Mara and Nairobi. Accessed on the November $15^{\text {th }} 2011$

Kessle, Daniel 1991 Birth Order, Family Size, and Achievement: Family Structure and Wage Determination. Journal of Labor Economics, 1991, vol 9, no.4.
Meera SN, Jhamtani A, and Rao DUM 2004 'Information and communication technologyin Agricultural development: a comparative analysis of three projects from India'. Agricultural Research and Extension Network. Network Paper No. 135, 13ppMidpoint economic review September, 2008:

http://ec.europa.eu/development/icenter/ repository/

Publication Coherence DEF en.pdf and National Population Commission of Nigeria (NPC), 2006: www.population.gov.ng

NFHP FCHV Survey Reports 2004, 2005, 2006.

Ohnishi M, Nakamura K and Takano T 2005 Improvement in maternal health literacyamong pregnant women who did not complete compulsory education: Policy implications for community care services. Health Policy, 72 (2), 157-164.

Quinones MA, Ford JK and Teach MS 1995 The relationship between work experience and job performance: A conceptual and meta-analytic review. Personnel Psych. 48(4) 887-910.

Ronsmans C, Khlat M 1999 Adolescence and risk of violent death during pregnancy in Matlab, Bangladesh. Lancet 1999, 354:1448.

Schmidt FL, Hunter JE 1998 The validity and utility of selection methods in personnel psychology: Practical and theoretical implications of 85 years of research findings. Psych. Bull. 124(2) 262-274.

Skirrbekk V 2003 Age and individual Productivity: A literature Survey, MPIDRWorking paper WP 2003-028.

Stuart TH 1993: Nutrition communication in the Philippines: the BIDANI experience. Paper presented at the FAO Inter country Workshop on Nutrition Education for South and East Asian Countries, 22-26 February 1993, Institute of Nutrition, Mahidol University, Thailand.

WHO 2005 Bulletin of the World Health OrganizationDecember 2005, 83 (12);www.who.int/ healthpromotion/conferences/6gchp/en/ $A c$ cessed September, 2011.

WHO 2004 E-Health for Health-care Delivery: Strategy 2004-2007. Geneva: WHO www.who.int/ eht/en/EHT strategy 2004-2007.pdf

State of the World's Children (2004): Girls, Education and Development. New York, United Nations Children's Fund, 2003.

WHO, UNICEF, UNFPA 1995 Estimate Maternal Mortality Report: Geneva, World Health Organization (Department of Reproductive Health and Research)

National Population Commission (NPC) 2006 www.population.gov.ng ac cessed 25th August 2011 